\title{
AN EFFECTIVE METHOD IN BEM FOR POTENTIAL PROBLEMS OF THIN BODIES
}

\author{
Yao-Ming Zhang \\ Institute of Applied Mathematics, Shandong University of Technology, Zibo, Shandong province, China, \\ zymfc@163.com \\ Yan Gu \\ Institute of Applied Mathematics, Shandong University of Technology, Zibo, Shandong province, China
}

Follow this and additional works at: https://jmstt.ntou.edu.tw/journal

Part of the Engineering Commons

\section{Recommended Citation}

Zhang, Yao-Ming and Gu, Yan (2010) "AN EFFECTIVE METHOD IN BEM FOR POTENTIAL PROBLEMS OF THIN BODIES," Journal of Marine Science and Technology: Vol. 18: Iss. 1, Article 17.

DOI: $10.51400 / 2709-6998.1875$

Available at: https://jmstt.ntou.edu.tw/journal/vol18/iss1/17

This Research Article is brought to you for free and open access by Journal of Marine Science and Technology. It has been accepted for inclusion in Journal of Marine Science and Technology by an authorized editor of Journal of Marine Science and Technology. 


\section{AN EFFECTIVE METHOD IN BEM FOR POTENTIAL PROBLEMS OF THIN BODIES}

\section{Acknowledgements}

The research is supported by the National Natural Science Foundation of China (10571110) and the Natural Science Foundation of Shandong Province of China (2003ZX12). The author wishes to express his gratitude with Professors JengTzong Chen and Chein-Shan Liu of Taiwan Ocean University for many valuable suggestions and directions 


\title{
AN EFFECTIVE METHOD IN BEM FOR POTENTIAL PROBLEMS OF THIN BODIES
}

\author{
Yao-Ming Zhang* and Yan $\mathrm{Gu}^{*}$
}

Key words: potential problem, thin body problem, BEM, nearly singular integrals.

\begin{abstract}
The study of the effective methods dealing with problems with thin domains is an important and a difficult issue in boundary element method (BEM). For the special structures of thin bodies, the singular and nearly singular integrals often occur simultaneously in boundary integral equations (BIEs). Therefore, the conventional boundary element method (CBEM) is invalid to obtain accurate results. This paper based on the indirect variable regularized BIEs of plane potential problems, and a nonlinear variable transformation is introduced in order to improve the rapid variations of nearly singular integrals. By doing these, the boundary singular and nearly singular integrals can all be evaluated effectively. Numerical examples demonstrate that the present method can deal with thin-body problems with the thickness-to-length ratios range from $1.0 \mathrm{E}-01$ to $1.0 \mathrm{E}-10$.
\end{abstract}

\section{INTRODUCTION}

Thin bodies, as a special structure, are frequently used for the design in various industrial applications, such as surface coated structures, thin shell-like structures, and cracks. However, the analysis of the behavior of these structures represents a very challenging and attractive task to scientists and engineers due to their special structures.

The BEM as an important numerical method has been widely used in many areas, but the accuracy of its calculation depends heavily on the computational precision of the singular and nearly singular integrals $[1-4,6,7,10,11,18,22,23]$. For non-thin body structures, there are two issues of major concern in BEM-based simulation. One is the estimation of singular integrals when the source point and the field point coincide; the other is known as the boundary layer effect when the physical quantities at the interior points very close to the boundary are calculated. However, for thin body structures,

Paper submitted 10/29/08; revised 12/23/08; accepted 03/30/09. Author for correspondence: Yao-Ming Zhang (e-mail: zymfc@163.com).

*Institute of Applied Mathematics, Shandong University of Technology, Zibo, Shandong province, China. some boundary elements will be very close to each other. Thus, the singular and nearly singular integrals need to be evaluated simultaneously when calculating the boundary unknown variables. Furthermore, almost all the field points are very close to the boundary and cannot be obtained accurately by Gauss quadrature. Consequently, the BEM analyses of thin body problems require not only the regularization BIEs to evaluate the singular integrals, but also an effective algorithm to calculate the nearly singular integrals.

Many technologies and methods of evaluating nearly singular integrals have been developed in recent years. Those methods can be divided on the whole into two categories: "indirect algorithms" and "direct algorithms". The indirect algorithms are mainly to calculate indirectly or avoid calculating the nearly singular integrals by establishing new regularized BIEs, such as virtual boundary element method $[21,27]$, rigid-body displacement method or the simple solution method [13], as well as other methods [5, 16, 19]. The direct algorithms are calculating the nearly singular integrals directly. They mainly include interval subdivision method [9], special Gaussian quadrature method [14], transformations methods $[8,15,26]$, and exact integration methods [17, 24, 28]. These methods obtained varying degree of success, but the questions still remain [26]. At the same time, the analysis of thin-body problems by BEM has also been consequentially carried out. Sladek et al. have obtained amount of the original results in this field. Non-singular integral equations for thin-walled structures are proposed based on a subtraction technique and mathematical regularization [20]. Liu et al. have undertaken a lot of researches [12] based on the non-linear coordinate transformation. Zhou et al. proposed semi-analytical and analytical integral algorithms to deal with thin-body problems $[29,30]$. It's necessary to point out that almost all the existing methods are based on the direct formulation. Thus the super-singular and nearly super-singular integrals should be dealt with in the solving process.

In this paper, the regularized BIEs [25] are combined with the nonlinear variable transformation [26] to analyze thin body problems. Owing to the special geometric shape of thin body structures, this combination is extraordinary. By doing these, the singular integrals can be estimated accurately by using the regularized BIEs, and the rapid variations of the nearly singular kernels can be smoothed out effectively by using the 
proposed nonlinear transformation. Then the singular and nearly singular integrals can all be evaluated accurately with conventional Gaussian quadrature. Two examples on heat conduction in thin domains with thickness-to-length ratios range from $1 \mathrm{E}-01$ to $1 \mathrm{E}-09$ are presented to test the proposed method. Both boundary unknown variables on the boundary and physical quantities at interior points are calculated, from which we can see that the suggested method is effective and feasible to deal with thin body problems.

\section{THE EQUIVALENT NONSINGULAR BOUNDARY INTEGRAL EQUATIONS}

In this paper, we always assume that $\Omega$ is a bounded domain in $R^{2}, \Omega^{c}$ its open complement domain, and $\Gamma=\partial \Omega$ their common boundary. In BEM, if boundary conditions are given properly, the domain variables can be computed by corresponding integral equations after the boundary quantities are all obtained. The equivalent non-singular BIEs with indirect variables are given in [25]. For the domain $\Omega$, the BIEs are given as

$$
\begin{gathered}
\int_{\Gamma} \phi(\boldsymbol{x}) d \Gamma_{x}+\int_{\Omega} f(\boldsymbol{x}) d \Omega=0 \\
u(\boldsymbol{y})=\int_{\Gamma} \phi(\boldsymbol{x}) u^{*}(\boldsymbol{x}, \boldsymbol{y}) d \Gamma_{x} \\
+\int_{\Omega} f(\boldsymbol{x}) u^{*}(\boldsymbol{x}, \boldsymbol{y}) d \Omega+C, \boldsymbol{y} \in \Gamma \\
\nabla u(\boldsymbol{y})=\phi(\boldsymbol{y})+\int_{\Gamma}[\phi(\boldsymbol{x})-\phi(\boldsymbol{y})] \nabla u^{*}(x, y) d \Gamma \\
-\phi(\boldsymbol{y})\left\{\int_{\Gamma}[\boldsymbol{t}(\boldsymbol{x})-\boldsymbol{t}(\boldsymbol{y})] \frac{\partial u^{*}(\boldsymbol{x}, \boldsymbol{y})}{\partial \boldsymbol{t}_{x}} d \Gamma\right. \\
\left.+\int_{\Gamma}[\boldsymbol{n}(\boldsymbol{x})-\boldsymbol{n}(\boldsymbol{y})] \frac{\partial u^{*}(\boldsymbol{x}, \boldsymbol{y})}{\partial \boldsymbol{n}_{x}} d \Gamma\right\} \\
+\int_{\Omega} f(\boldsymbol{x}) \nabla u^{*}(\boldsymbol{x}, \boldsymbol{y}) d \Omega
\end{gathered}
$$

where $\boldsymbol{t}(\boldsymbol{x}), \boldsymbol{n}(\boldsymbol{x})$ are the unit tangent and outward normal vectors of $\Gamma$ to domain $\Omega$ at point $\boldsymbol{x}$ respectively.

For the domain $\Omega^{c}$, the equations are given as

$$
\begin{gathered}
\int_{\Gamma} \phi(\boldsymbol{x}) d \Gamma_{\boldsymbol{x}}+\int_{\Omega_{c}} f(\boldsymbol{x}) d \Omega^{c}=0 \\
u(\boldsymbol{y})=\int_{\Gamma} \phi(\boldsymbol{x}) u^{*}(\boldsymbol{x}, \boldsymbol{y}) d \Gamma_{\boldsymbol{x}} \\
\quad+\int_{\Omega^{c}} f(\boldsymbol{x}) u^{*}(\boldsymbol{x}, \boldsymbol{y}) d \Omega^{c}+C, \boldsymbol{y} \in \Gamma
\end{gathered}
$$

$$
\begin{aligned}
\nabla_{y} u(\boldsymbol{y})= & \int_{\Gamma}[\phi(\boldsymbol{x})-\phi(\boldsymbol{y})] \nabla_{y} u^{*}(\boldsymbol{x}, \boldsymbol{y}) d \Gamma_{\boldsymbol{x}} \\
& -\phi(\boldsymbol{y})\left\{\int_{\Gamma}\left[\boldsymbol{t}^{c}(\boldsymbol{x})-\boldsymbol{t}^{c}(\boldsymbol{y})\right] \nabla u^{*}(\boldsymbol{x}, \boldsymbol{y}) \cdot \boldsymbol{t}^{c}(\boldsymbol{x}) d \Gamma_{\boldsymbol{x}}\right. \\
& \left.+\int_{\Gamma}\left[\boldsymbol{n}^{c}(\boldsymbol{x})-\boldsymbol{n}^{c}(\boldsymbol{y})\right] \nabla u^{*}(\boldsymbol{x}, \boldsymbol{y}) \cdot \boldsymbol{n}^{c}(\boldsymbol{x}) d \Gamma_{\boldsymbol{x}}\right\} \\
& +\int_{\Omega^{c}} f(\boldsymbol{x}) \nabla_{\boldsymbol{y}} u^{*}(\boldsymbol{x}, \boldsymbol{y}) d \boldsymbol{\Omega}^{c}
\end{aligned}
$$

where $\boldsymbol{t}^{c}(\boldsymbol{x}), \boldsymbol{n}^{c}(\boldsymbol{x})$ are the unit tangent and outward normal vectors of $\Gamma$ to domain $\Omega^{c}$ at point $\boldsymbol{x}$ respectively.

For the interior point $y$, the integral equations can be written as

$$
\begin{aligned}
u(\boldsymbol{y})= & \int_{\Gamma} \phi(\boldsymbol{x}) u^{*}(\boldsymbol{x}, \boldsymbol{y}) d \Gamma \\
& +\int_{\hat{\Omega}} f(\boldsymbol{x}) u^{*}(\boldsymbol{x}, \boldsymbol{y}) d \hat{\boldsymbol{\Omega}}+C, \boldsymbol{y} \in \hat{\boldsymbol{\Omega}} \\
\nabla u(\boldsymbol{y})= & \int_{\Gamma} \phi(\boldsymbol{x}) \nabla_{y} u^{*}(\boldsymbol{x}, \boldsymbol{y}) d \Gamma \\
& +\int_{\hat{\Omega}} f(\boldsymbol{x}) \nabla_{y} u^{*}(\boldsymbol{x}, \boldsymbol{y}) d \hat{\boldsymbol{\Omega}}, \boldsymbol{y} \in \hat{\boldsymbol{\Omega}}
\end{aligned}
$$

In (1)-(8), $\phi(x)$ is the density function to be determined, $f(x)$ the body function, and in (7) and (8) $\hat{\Omega}=\Omega$ or $\Omega^{c}$.

The density function $\phi(x)$ and boundary quantities can be obtained via (1)-(3) or (4)-(6). However, if the domain of the problem is thin, the distance $r$ between some boundary nodes and integral elements probably approaches zero. This would cause nearly singular integrals in (2)-(3) and (5)-(6), and the boundary unknowns cannot be calculated accurately by Gauss quadrature. On the other hand, the field points are usually very close to the integral elements for thin-body problems. Therefore, there also exist nearly singular integrals in (7)-(8). These integrals can be expressed as

$$
I_{1}=\int_{\Gamma} \varphi(x) \ln r^{2} d \Gamma, I_{2}=\int_{\Gamma} \varphi(x) \frac{1}{r^{2 \alpha}} d \Gamma
$$

where $\alpha>0$ and $\varphi(\boldsymbol{x})$ is a well-behaved function. Obviously, the nearly singularities of the integrals in (9) come form the distance $r$.

\section{THE TRANSFORMATION OF NEARLY SINGULAR INTEGRAL}

\section{Linear Element Approximation of the Boundary $\Gamma$}

Assuming $\boldsymbol{x}^{1}=\left(x_{1}^{1}, x_{2}^{1}\right), \boldsymbol{x}^{2}=\left(x_{1}^{2}, x_{2}^{2}\right)$ are the two extreme points of the linear element $\Gamma_{j}$, then the element $\Gamma_{j}$ can be expressed as

$$
x_{k}(\xi)=N_{1}(\xi) x_{k}^{1}+N_{2}(\xi) x_{k}^{2}, \xi \in[-1,1], k=1,2
$$

here $N_{1}(\xi)=(1-\xi) / 2, N_{2}(\xi)=(1+\xi) / 2$. Letting $s_{i}=x_{i}^{2}-x_{i}^{1}$, $w_{i}=y_{i}-\left(x_{i}^{2}+x_{i}^{1}\right) / 2$, one has 


$$
\begin{aligned}
r_{, i}=\frac{r_{i}}{r}=\frac{y_{i}-x_{i}}{r}=\frac{s_{i} \xi / 2+w_{i}}{r} \\
r^{2}=|\boldsymbol{x}-\boldsymbol{y}|^{2}=r_{i} r_{i}=A \xi^{2}+B \xi+E \\
=L^{2}\left[(\xi-\eta)^{2}+d^{2}\right]
\end{aligned}
$$

where $A=s_{i} s_{i} / 4, B=s_{i} w_{i}, E=w_{i} w_{i}, \eta=-B / 2 A, L=\sqrt{A}$, $d=\sqrt{4 A E-B^{2}} / 2 A$.

The integrals $I_{1}$ and $I_{2}$ in (9) can be divided into two parts at point $\eta$ as follows

$$
\begin{aligned}
& I_{1}=\left\{\int_{-1}^{\eta}+\int_{\eta}^{1}\right\} g(\xi) \ln \left[(\xi-\eta)^{2}+d^{2}\right] d \xi \\
&+\ln L^{2} \int_{-1}^{1} g(\xi) d \xi \\
& I_{2}=\left\{\int_{-1}^{\eta}+\int_{\eta}^{1}\right\} \frac{g(\xi)}{L^{2 \alpha}\left[(\xi-\eta)^{2}+d^{2}\right]^{\alpha}} d \xi
\end{aligned}
$$

where $g(\cdot)$ is a regular function that consists of shape function and Jacobian.

\section{2. "Arc Element" Approximation of the Boundary $\Gamma$}

In engineering applications, the structures with circle or ellipse boundaries are widely used in order to avoid stress concentration. Suppose $\left(R, \theta_{1}\right),\left(R, \theta_{2}\right)$ are the coordinates of the two extreme points of the arc element $\Gamma_{j}$ respectively. Then the element $\Gamma_{j}$ can be expressed as [25]

$$
\left\{\begin{array}{l}
x_{1}=R \cos \theta \\
x_{2}=R \sin \theta
\end{array}, \theta=\frac{1-\xi}{2} \theta_{1}+\frac{1+\xi}{2} \theta_{2}, \xi \in[-1,1]\right.
$$

For the interior point $y=\left(R_{0} \cos \theta_{0}, R_{0} \sin \theta_{0}\right), \theta_{1}<\theta_{0}<\theta_{2}$ Then $\theta_{0}=\frac{1-\eta}{2} \theta_{1}+\frac{1+\eta}{2} \theta_{2}$, thus

$$
r^{2}=|\boldsymbol{x}-\boldsymbol{y}|^{2}=4 R R_{0}\left\{\sin ^{2}[\beta(\xi-\eta)]+d^{2}\right\}
$$

here $\gamma=\beta(\xi-\eta), \beta=\frac{\theta_{2}-\theta_{1}}{4}, d=\frac{R-R_{0}}{4 \sqrt{R R_{0}}}$.

The integrals $I_{1}$ and $I_{2}$ in (9) can be divided into two parts at point $\eta$ as follows

$$
\begin{aligned}
I_{1}= & \left\{\int_{-1}^{\eta}+\int_{\eta}^{1}\right\} g(\xi) \ln \left(\sin ^{2} \gamma+d^{2}\right) d \xi \\
& +\ln L^{2} \int_{-1}^{1} g(\xi) d \xi \\
I_{2}= & \frac{1}{L^{2 \alpha}}\left\{\int_{-1}^{\eta}+\int_{\eta}^{1}\right\} \frac{g(\xi)}{\left(\sin ^{2} \gamma+d^{2}\right)^{\alpha}} d \xi
\end{aligned}
$$

where $L=2 \sqrt{R R_{0}}$ and $g(\cdot)$ is the regular function that consists of shape function and Jacobian.

\section{The Transformation}

The integrals $I_{1}$ and $I_{2}$ in (13), (14), (16), and (17) can be reduced to the following integrals by simple deduction

$$
\begin{gathered}
T_{1}=\int_{0}^{A} g(x) \ln \left(x^{2}+d^{2}\right) d x, \\
T_{2}=\int_{0}^{A} \frac{g(x)}{\left(x^{2}+d^{2}\right)^{\alpha}} d x
\end{gathered}
$$

Adopting the following variable transformation

$$
x=d\left(e^{k(1+t)}-1\right), t \in[-1,1], k=\ln \sqrt{1+A / d}
$$

Equation (18) can be rewritten as

$$
\begin{aligned}
T_{1}= & d k \int_{-1}^{1} g(t) \ln d^{2} e^{k(1+t)} d t \\
& +d k \int_{-1}^{1} g(t) \ln \left[\left(e^{k(1+t)}-1\right)^{2}+1\right] e^{k(1+t)} d t \\
T_{2}= & d^{1-2 \alpha} k \int_{-1}^{1} \frac{g(t) e^{k(1+t)}}{\left[\left(e^{k(1+t)}-1\right)^{2}+1\right]^{\alpha}} d t
\end{aligned}
$$

The final integral formulations are obtained as shown in (19), which can now be calculated accurately by standard Gaussian quadrature.

\section{NUMERICAL EXAMPLES}

Two examples on heat conduction in thin domains are presented in this section to test the proposed method. Boundary unknown variables on the boundary and physical quantities at interior points are both calculated. Only the Gaussian quadrature is used to calculate the numerical integrals, including the nearly singular integrals.

Example 1. Heat conduction in a thin cylinder is considered. The inner and outer radii of the cylinder is $a=10$ and $b$ respectively. The boundary conditions are given in Fig. 1.

Eighty arc elements are divided on the boundaries totally. Thirty-four arc elements are divided on the inner and outer cylinders, and six are on the two short straight boundaries.

Linear discontinuous interpolation is adopted to approximate the boundary functions. In this example, $(b-a) / a$ is defined as the thickness-to-length ratio [29].

For different thickness-to-length ratio, Table 1 and Table 2 show that the potential at boundary node $A$ can be well calculated by the present method and CBEM. However, the flux results calculated by the CBEM at the node $B$ begin to degenerate when the thickness-to-length ratio less than $1.0 \mathrm{E}-02$. In contrast, the present method can be used to calculate the 
Table 1. Temperatures at the boundary node $A$.

\begin{tabular}{cccccc}
\hline$(b-a) / a$ & Exact & CBEM & Relative error $(\%)$ & Present & Relative error $(\%)$ \\
\hline $1.0 \mathrm{E}-01$ & $-0.1600000 \mathrm{E}+03$ & $-0.1600002 \mathrm{E}+03$ & $-0.1367549 \mathrm{E}-03$ & $-0.1600002 \mathrm{E}+03$ & $-0.1367549 \mathrm{E}-03$ \\
$1.0 \mathrm{E}-02$ & $-0.1437550 \mathrm{E}+03$ & $-0.1437477 \mathrm{E}+03$ & $0.5103898 \mathrm{E}-02$ & $-0.1437516 \mathrm{E}+03$ & $0.2373698 \mathrm{E}-02$ \\
$1.0 \mathrm{E}-03$ & $-0.1421750 \mathrm{E}+03$ & $-0.1417780 \mathrm{E}+03$ & $0.2792951 \mathrm{E}+00$ & $-0.1421704 \mathrm{E}+03$ & $0.3246838 \mathrm{E}-02$ \\
$1.0 \mathrm{E}-04$ & $-0.1420175 \mathrm{E}+03$ & $-0.1413651 \mathrm{E}+03$ & $0.4593660 \mathrm{E}+00$ & $-0.1420128 \mathrm{E}+03$ & $0.3339321 \mathrm{E}-02$ \\
$1.0 \mathrm{E}-05$ & $-0.1420018 \mathrm{E}+03$ & $-0.1413419 \mathrm{E}+03$ & $0.4646742 \mathrm{E}+00$ & $-0.1419970 \mathrm{E}+03$ & $0.3348576 \mathrm{E}-02$ \\
$1.0 \mathrm{E}-06$ & $-0.1420002 \mathrm{E}+03$ & $-0.1413403 \mathrm{E}+03$ & $0.4647293 \mathrm{E}+00$ & $-0.1419954 \mathrm{E}+03$ & $0.3349502 \mathrm{E}-02$ \\
$1.0 \mathrm{E}-07$ & $-0.1420000 \mathrm{E}+03$ & $-0.1413401 \mathrm{E}+03$ & $0.4647299 \mathrm{E}+00$ & $-0.1419953 \mathrm{E}+03$ & $0.3349594 \mathrm{E}-02$ \\
$1.0 \mathrm{E}-08$ & $-0.1420000 \mathrm{E}+03$ & $-0.1413401 \mathrm{E}+03$ & $0.4647299 \mathrm{E}+00$ & $-0.1419952 \mathrm{E}+03$ & $0.3349604 \mathrm{E}-02$ \\
$1.0 \mathrm{E}-09$ & $-0.1420000 \mathrm{E}+03$ & $-0.1413401 \mathrm{E}+03$ & $0.4647299 \mathrm{E}+00$ & $-0.1419952 \mathrm{E}+03$ & $0.3349605 \mathrm{E}-02$ \\
$1.0 \mathrm{E}-10$ & $-0.1420000 \mathrm{E}+03$ & $-0.1413401 \mathrm{E}+03$ & $0.4647299 \mathrm{E}+00$ & $-0.1419952 \mathrm{E}+03$ & $0.3349605 \mathrm{E}-02$ \\
\hline
\end{tabular}

Table 2. Normal gradients at the boundary node $B$.

\begin{tabular}{cccccc}
\hline$(b-a) / a$ & Exact & CBEM & Relative error $(\%)$ & Present & Relative error $(\%)$ \\
\hline $1.0 \mathrm{E}-1$ & $-0.4300000 \mathrm{E}+02$ & $-0.4296942 \mathrm{E}+02$ & $0.7111454 \mathrm{E}-01$ & $-0.4296942 \mathrm{E}+02$ & $0.7111454 \mathrm{E}-01$ \\
$1.0 \mathrm{E}-2$ & $-0.4300000 \mathrm{E}+02$ & $-0.4297181 \mathrm{E}+02$ & $0.6555491 \mathrm{E}-01$ & $-0.4297172 \mathrm{E}+02$ & $0.6576947 \mathrm{E}-01$ \\
$1.0 \mathrm{E}-3$ & $-0.4300000 \mathrm{E}+02$ & $-0.1257396 \mathrm{E}+03$ & $-0.1924176 \mathrm{E}+03$ & $-0.4296923 \mathrm{E}+02$ & $0.7155983 \mathrm{E}-01$ \\
$1.0 \mathrm{E}-4$ & $-0.4300000 \mathrm{E}+02$ & $0.3594451 \mathrm{E}+01$ & $0.1083592 \mathrm{E}+03$ & $-0.4296865 \mathrm{E}+02$ & $0.7290199 \mathrm{E}-01$ \\
$1.0 \mathrm{E}-5$ & $-0.4300000 \mathrm{E}+02$ & $0.3649202 \mathrm{E}-01$ & $0.1000849 \mathrm{E}+03$ & $-0.4296859 \mathrm{E}+02$ & $0.7305539 \mathrm{E}-01$ \\
$1.0 \mathrm{E}-6$ & $-0.4300000 \mathrm{E}+02$ & $0.5539044 \mathrm{E}-03$ & $0.1000013 \mathrm{E}+03$ & $-0.4296838 \mathrm{E}+02$ & $0.7352498 \mathrm{E}-01$ \\
$1.0 \mathrm{E}-7$ & $-0.4300000 \mathrm{E}+02$ & $-0.1047532 \mathrm{E}-02$ & $0.9999756 \mathrm{E}+02$ & $-0.4296336 \mathrm{E}+02$ & $0.8520952 \mathrm{E}-01$ \\
$1.0 \mathrm{E}-8$ & $-0.4300000 \mathrm{E}+02$ & $-0.1734616 \mathrm{E}-02$ & $0.9999597 \mathrm{E}+02$ & $-0.4296412 \mathrm{E}+02$ & $0.8345282 \mathrm{E}-01$ \\
$1.0 \mathrm{E}-9$ & $-0.4300000 \mathrm{E}+02$ & $0.3270279 \mathrm{E}-02$ & $0.1000076 \mathrm{E}+03$ & $-0.4295924 \mathrm{E}+02$ & $0.9478312 \mathrm{E}-01$ \\
$1.0 \mathrm{E}-10$ & $-0.4300000 \mathrm{E}+02$ & $0.1252932 \mathrm{E}-01$ & $0.1000291 \mathrm{E}+03$ & $-0.4294596 \mathrm{E}+02$ & $0.1256806 \mathrm{E}+00$ \\
\hline
\end{tabular}

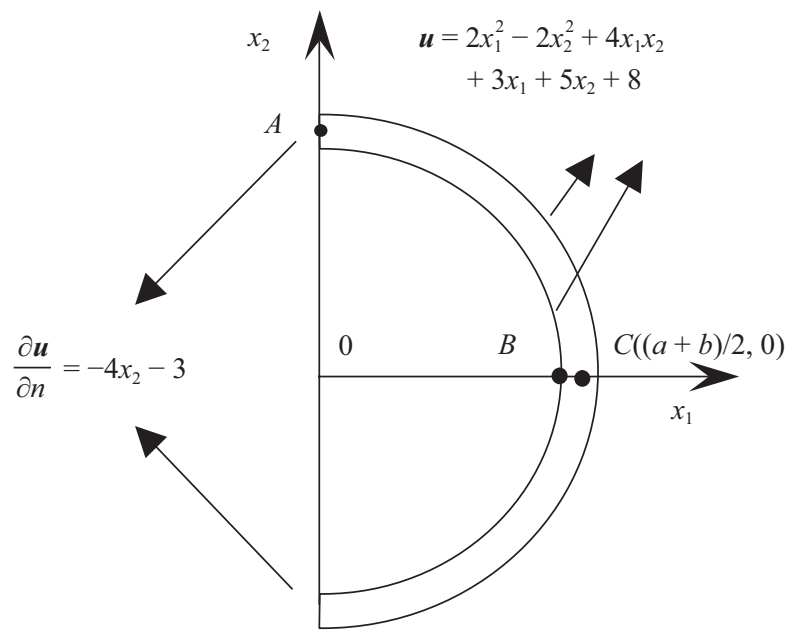

Fig. 1. A thin-walled ring.

fluxes accurately even when the thickness-to-length ratio as small as 1.0E-10. The above analysis indicates that the CBEM can only be available to calculate the acceptable boundary unknown variables for the thickness-to-length ratio down to 1.0E-02. Nevertheless, the present method can obtain the accurate results even when the thickness-to-length ratio as small as 1.0E-10.

Table 3 gives the results of fluxes at interior point $C$ for different thickness-to-length ratio, from which it can be seen that the CBEM begin to degenerate when the thickness-tolength ratio down to $1.0 \mathrm{E}-02$, with further decrease of the thickness-to-length ratio, the results are out of true. However, the results obtained by using the present method are excellently consistent with the analytical solutions even when the thickness-to-length ratio equals 1.0E-09. The dates in Table 4 further demonstrate the effectiveness of the present method when the interior points gradually close to the boundary with thickness-to-length ratio equals 1.0E-09.

For different thickness-to-length ratio, the temperature errors at interior point $C$ are shown in Fig. 2. It can be seen that the potential results obtained by using the present method are in good agreement with the exact solutions.

The convergence curves of computed fluxes at interior points $B$ and $C$ are shown in Fig. 3, from which we can observe that the convergence speeds are still fast even when the thickness-to-length ratio reached 1.0E-09.

Example 2. Heat conduction in a thin rectangle is considered. The length and width of the rectangular are $a=1$ and $b$. The boundary conditions are given in Fig. 4.

Thirty arc elements are divided on the two long sides totally, and only two elements are divided on the two short sides for their little length. Therefore, the total number of the element is 
Table 3. Fluxes $\partial u / \partial x_{1}$ at the interior node $C$.

\begin{tabular}{cccccc}
\hline$(b-a) / a$ & Exact & CBEM & Relative error $(\%)$ & Present & Relative error $(\%)$ \\
\hline $1.0 \mathrm{E}-01$ & $0.4500000 \mathrm{E}+02$ & $0.4499943 \mathrm{E}+02$ & $0.1270766 \mathrm{E}-02$ & $0.4499943 \mathrm{E}+02$ & $0.1270766 \mathrm{E}-02$ \\
$1.0 \mathrm{E}-02$ & $0.4320000 \mathrm{E}+02$ & $0.4268257 \mathrm{E}+02$ & $0.1197752 \mathrm{E}+01$ & $0.4317559 \mathrm{E}+02$ & $0.5650029 \mathrm{E}-01$ \\
$1.0 \mathrm{E}-03$ & $0.4302000 \mathrm{E}+02$ & $0.2008537 \mathrm{E}+02$ & $0.5331156 \mathrm{E}+02$ & $0.4298930 \mathrm{E}+02$ & $0.7135087 \mathrm{E}-01$ \\
$1.0 \mathrm{E}-04$ & $0.4300200 \mathrm{E}+02$ & $-0.1064946 \mathrm{E}+00$ & $0.1002477 \mathrm{E}+03$ & $0.4297069 \mathrm{E}+02$ & $0.7281246 \mathrm{E}-01$ \\
$1.0 \mathrm{E}-05$ & $0.4300020 \mathrm{E}+02$ & $-0.1021886 \mathrm{E}-02$ & $0.1000024 \mathrm{E}+03$ & $0.4296872 \mathrm{E}+02$ & $0.7320819 \mathrm{E}-01$ \\
$1.0 \mathrm{E}-06$ & $0.4300002 \mathrm{E}+02$ & $-0.1021467 \mathrm{E}-04$ & $0.1000000 \mathrm{E}+03$ & $0.4296856 \mathrm{E}+02$ & $0.7317052 \mathrm{E}-01$ \\
$1.0 \mathrm{E}-07$ & $0.4300000 \mathrm{E}+02$ & $-0.1021430 \mathrm{E}-06$ & $0.1000000 \mathrm{E}+03$ & $0.4297031 \mathrm{E}+02$ & $0.6905575 \mathrm{E}-01$ \\
$1.0 \mathrm{E}-08$ & $0.4300000 \mathrm{E}+02$ & $-0.1023443 \mathrm{E}-08$ & $0.1000000 \mathrm{E}+03$ & $0.4296983 \mathrm{E}+02$ & $0.7016518 \mathrm{E}-01$ \\
$1.0 \mathrm{E}-09$ & $0.4300000 \mathrm{E}+02$ & $-0.9865553 \mathrm{E}-11$ & $0.1000000 \mathrm{E}+03$ & $0.4296284 \mathrm{E}+02$ & $0.8640969 \mathrm{E}-01$ \\
$1.0 \mathrm{E}-10$ & $0.4300000 \mathrm{E}+02$ & $0.4707623 \mathrm{E}-12$ & $0.1000000 \mathrm{E}+03$ & $0.4295324 \mathrm{E}+02$ & $0.1087370 \mathrm{E}+00$ \\
\hline
\end{tabular}

Table 4. Fluxes $\partial u / \partial x_{1}$ on the line $x_{2}=0$ when $(b-a) / a=1.0 \mathrm{E}-09$.

\begin{tabular}{cccccc}
\hline$x_{1}$ & Exact & CBEM & Relative error $(\%)$ & Present & Relative error $(\%)$ \\
\hline 10.000000001 & $0.4300000 \mathrm{E}+02$ & $0.8931400 \mathrm{E}-05$ & $0.9999998 \mathrm{E}+02$ & $0.4296523 \mathrm{E}+02$ & $0.8087179 \mathrm{E}-01$ \\
10.000000002 & $0.4300000 \mathrm{E}+02$ & $0.6698547 \mathrm{E}-05$ & $0.9999998 \mathrm{E}+02$ & $0.4296477 \mathrm{E}+02$ & $0.8193783 \mathrm{E}-01$ \\
10.000000003 & $0.4300000 \mathrm{E}+02$ & $0.4465695 \mathrm{E}-05$ & $0.9999999 \mathrm{E}+02$ & $0.4296423 \mathrm{E}+02$ & $0.8317615 \mathrm{E}-01$ \\
10.000000004 & $0.4300000 \mathrm{E}+02$ & $0.2232842 \mathrm{E}-05$ & $0.9999999 \mathrm{E}+02$ & $0.4296360 \mathrm{E}+02$ & $0.8464009 \mathrm{E}-01$ \\
10.000000005 & $0.4300000 \mathrm{E}+02$ & $-0.9865553 \mathrm{E}-11$ & $0.1000000 \mathrm{E}+03$ & $0.4296284 \mathrm{E}+02$ & $0.8640969 \mathrm{E}-01$ \\
10.000000006 & $0.4300000 \mathrm{E}+02$ & $-0.2232862 \mathrm{E}-05$ & $0.1000000 \mathrm{E}+03$ & $0.4296189 \mathrm{E}+02$ & $0.8862007 \mathrm{E}-01$ \\
10.000000007 & $0.4300000 \mathrm{E}+02$ & $-0.4465715 \mathrm{E}-05$ & $0.1000000 \mathrm{E}+03$ & $0.4296065 \mathrm{E}+02$ & $0.9150921 \mathrm{E}-01$ \\
10.000000008 & $0.4300000 \mathrm{E}+02$ & $-0.6698567 \mathrm{E}-05$ & $0.1000000 \mathrm{E}+03$ & $0.4295890 \mathrm{E}+02$ & $0.9557602 \mathrm{E}-01$ \\
10.000000009 & $0.4300000 \mathrm{E}+02$ & $-0.8931419 \mathrm{E}-05$ & $0.1000000 \mathrm{E}+03$ & $0.4295607 \mathrm{E}+02$ & $0.1021645 \mathrm{E}+00$ \\
\hline
\end{tabular}

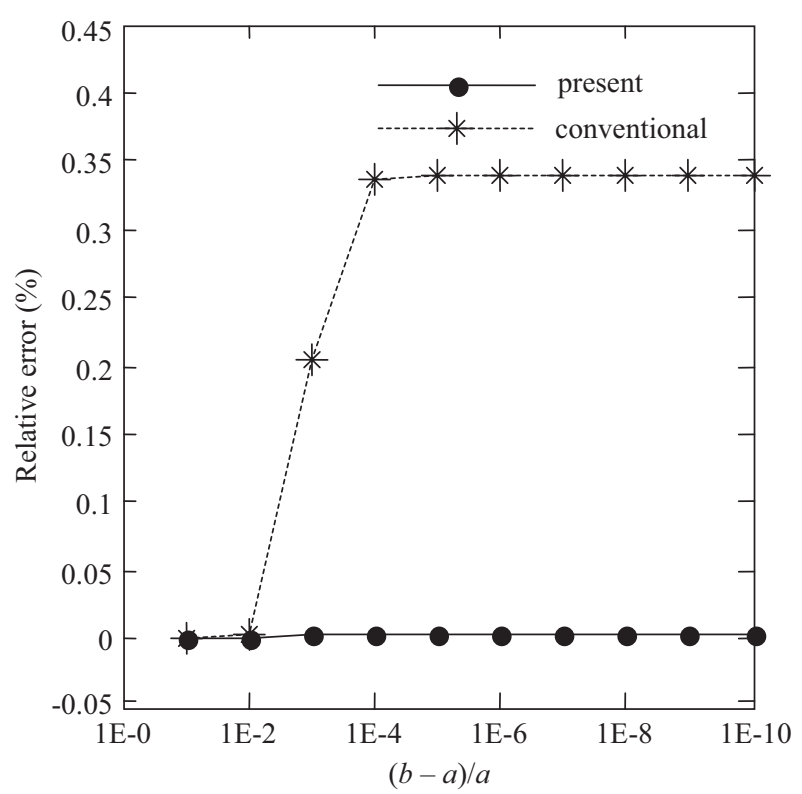

Fig. 2. Temperature errors at interior point $C$.

32. As we all know, the evaluation of fluxes would be more difficult than that of potential and, therefore, only the flux results are listed. The normal gradients on the boundary are given in Table 5. The flux results at interior points are given in Table 6 and Fig. 5. The convergence curve of fluxes at interior

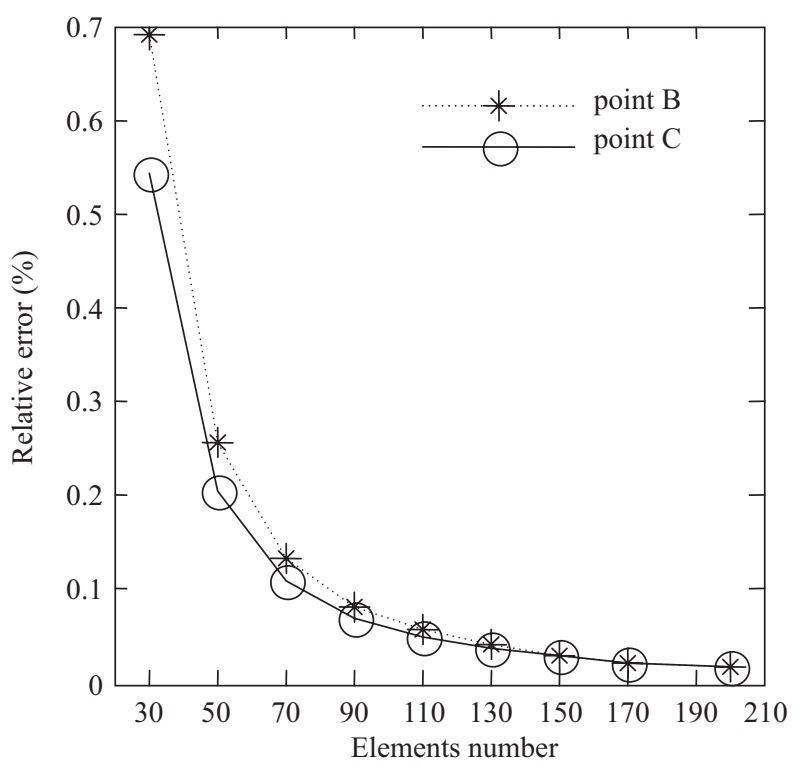

Fig. 3. Convergence curves of fluxes at points $B$ and $C$ with $(b-a) / a=$ $1.0 \mathrm{E}-09$.

point is shown in Fig. 6. In this example, we defined $b / a$ is the thickness-to-length ratio [29].

Table 5 shows that the flux results calculated by the CBEM at the boundary node $D$ become completely invalid when the thickness-to-length ratio equals $1.0 \mathrm{E}-03$. In contrast with the 
Table 5. Normal gradients at the boundary node $D$.

\begin{tabular}{cccccc}
\hline $\mathrm{b} / \mathrm{a}$ & Exact & CBEM & Relative error $(\%)$ & Present & Relative error $(\%)$ \\
\hline $1.0 \mathrm{E}-01$ & $-0.7750000 \mathrm{E}+01$ & $-0.7749404 \mathrm{E}+01$ & $0.7684617 \mathrm{E}-02$ & $-0.7749604 \mathrm{E}+01$ & $0.5109677 \mathrm{E}-02$ \\
$1.0 \mathrm{E}-02$ & $-0.7750000 \mathrm{E}+01$ & $-0.7749052 \mathrm{E}+01$ & $0.1223317 \mathrm{E}-01$ & $-0.7749910 \mathrm{E}+01$ & $0.1161223 \mathrm{E}-02$ \\
$1.0 \mathrm{E}-03$ & $-0.7750000 \mathrm{E}+01$ & $-0.1067220 \mathrm{E}+02$ & $-0.3770577 \mathrm{E}+02$ & $-0.7749989 \mathrm{E}+01$ & $0.1419354 \mathrm{E}-03$ \\
$1.0 \mathrm{E}-04$ & $-0.7750000 \mathrm{E}+01$ & $0.8987383 \mathrm{E}+00$ & $0.1115966 \mathrm{E}+03$ & $-0.7749987 \mathrm{E}+01$ & $0.1728589 \mathrm{E}-03$ \\
$1.0 \mathrm{E}-05$ & $-0.7750000 \mathrm{E}+01$ & $-0.7221865 \mathrm{E}+00$ & $0.9068146 \mathrm{E}+02$ & $-0.7749979 \mathrm{E}+01$ & $0.2709677 \mathrm{E}-03$ \\
$1.0 \mathrm{E}-06$ & $-0.7750000 \mathrm{E}+01$ & $-0.8789177 \mathrm{E}+00$ & $0.8865913 \mathrm{E}+02$ & $-0.7749991 \mathrm{E}+01$ & $0.1161290 \mathrm{E}-03$ \\
$1.0 \mathrm{E}-07$ & $-0.7750000 \mathrm{E}+01$ & $-0.8945172 \mathrm{E}+00$ & $0.8845784 \mathrm{E}+02$ & $-0.7749973 \mathrm{E}+01$ & $0.3467598 \mathrm{E}-03$ \\
$1.0 \mathrm{E}-08$ & $-0.7750000 \mathrm{E}+01$ & $-0.8960764 \mathrm{E}+00$ & $0.8843772 \mathrm{E}+02$ & $-0.7750015 \mathrm{E}+01$ & $-0.1949624 \mathrm{E}-03$ \\
$1.0 \mathrm{E}-09$ & $-0.7750000 \mathrm{E}+01$ & $-0.8962323 \mathrm{E}+00$ & $0.8843571 \mathrm{E}+02$ & $-0.7750183 \mathrm{E}+01$ & $-0.2361732 \mathrm{E}-02$ \\
$1.0 \mathrm{E}-10$ & $-0.7750000 \mathrm{E}+01$ & $-0.8962479 \mathrm{E}+00$ & $0.8843551 \mathrm{E}+02$ & $-0.7750283 \mathrm{E}+01$ & $-0.3656933 \mathrm{E}-02$ \\
\hline
\end{tabular}

Table 6. Fluxes $\partial u / \partial x_{1}$ at the interior points on the line $x_{1}=0.3$ when $b / a=1.0 \mathrm{E}-09$.

\begin{tabular}{cccccc}
\hline$x_{2}$ & Exact & CBEM & Relative error $(\%)$ & Present & Relative error $(\%)$ \\
\hline $1.0 \mathrm{E}-10$ & $-0.2200000 \mathrm{E}+01$ & $-0.4007663 \mathrm{E}+01$ & $-0.8216651 \mathrm{E}+02$ & $-0.2201486 \mathrm{E}+01$ & $-0.6756812 \mathrm{E}-01$ \\
$2.0 \mathrm{E}-10$ & $-0.2200000 \mathrm{E}+01$ & $-0.4007663 \mathrm{E}+01$ & $-0.8216651 \mathrm{E}+02$ & $-0.2201486 \mathrm{E}+01$ & $-0.6754774 \mathrm{E}-01$ \\
$3.0 \mathrm{E}-10$ & $-0.2200000 \mathrm{E}+01$ & $-0.4007663 \mathrm{E}+01$ & $-0.8216651 \mathrm{E}+02$ & $-0.2201486 \mathrm{E}+01$ & $-0.6753649 \mathrm{E}-01$ \\
$4.0 \mathrm{E}-10$ & $-0.2200000 \mathrm{E}+01$ & $-0.4007663 \mathrm{E}+01$ & $-0.8216651 \mathrm{E}+02$ & $-0.2201486 \mathrm{E}+01$ & $-0.6753603 \mathrm{E}-01$ \\
$5.0 \mathrm{E}-10$ & $-0.2200000 \mathrm{E}+01$ & $-0.4007663 \mathrm{E}+01$ & $-0.8216651 \mathrm{E}+02$ & $-0.2201486 \mathrm{E}+01$ & $-0.6753295 \mathrm{E}-01$ \\
$6.0 \mathrm{E}-10$ & $-0.2200000 \mathrm{E}+01$ & $-0.4007663 \mathrm{E}+01$ & $-0.8216651 \mathrm{E}+02$ & $-0.2201486 \mathrm{E}+01$ & $-0.6753090 \mathrm{E}-01$ \\
$7.0 \mathrm{E}-10$ & $-0.2200000 \mathrm{E}+01$ & $-0.4007663 \mathrm{E}+01$ & $-0.8216650 \mathrm{E}+02$ & $-0.2201486 \mathrm{E}+01$ & $-0.6753139 \mathrm{E}-01$ \\
$8.0 \mathrm{E}-10$ & $-0.2200000 \mathrm{E}+01$ & $-0.4007663 \mathrm{E}+01$ & $-0.8216650 \mathrm{E}+02$ & $-0.2201486 \mathrm{E}+01$ & $-0.6752422 \mathrm{E}-01$ \\
$9.0 \mathrm{E}-10$ & $-0.2200000 \mathrm{E}+01$ & $-0.4007663 \mathrm{E}+01$ & $-0.8216650 \mathrm{E}+02$ & $-0.2201486 \mathrm{E}+01$ & $-0.6754076 \mathrm{E}-01$ \\
\hline
\end{tabular}

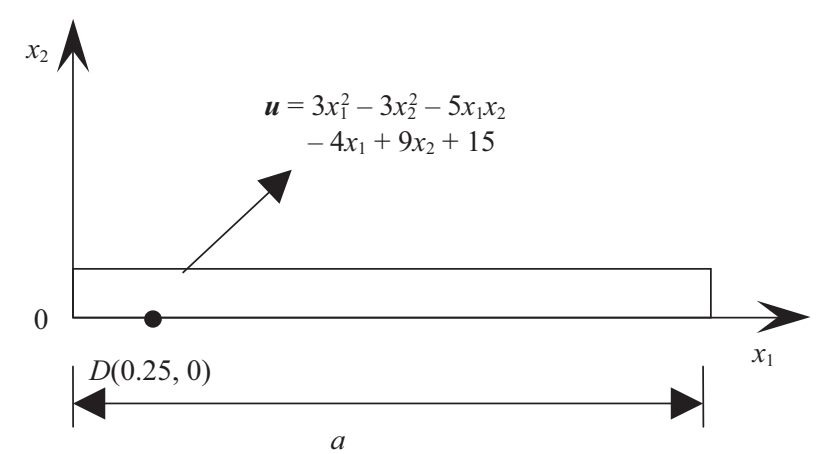

Fig. 4. A thin rectangular domain.

CBEM, the present method can be used to calculate the fluxes accurately even when the thickness-to-length ratio down to $1.0 \mathrm{E}-10$.

The flux results at interior points are shown in Table 6 and Fig. 5. It can be observed that the flux results calculated by present method represent a high degree of accuracy and stability. In addition, as shown in Fig. 6, the convergence speeds of the computed fluxes still fast even when the thickness-to-length ratio gets down to $1.0 \mathrm{E}-09$.

According to the above analysis, the results computed by the CBEM become less satisfactory when the thickness-to-length ratio less than 1.0E-02. In contrast, the results calculated by present method are still satisfactory even when the thickness-to-length ratio as small as $1.0 \mathrm{E}-09$.

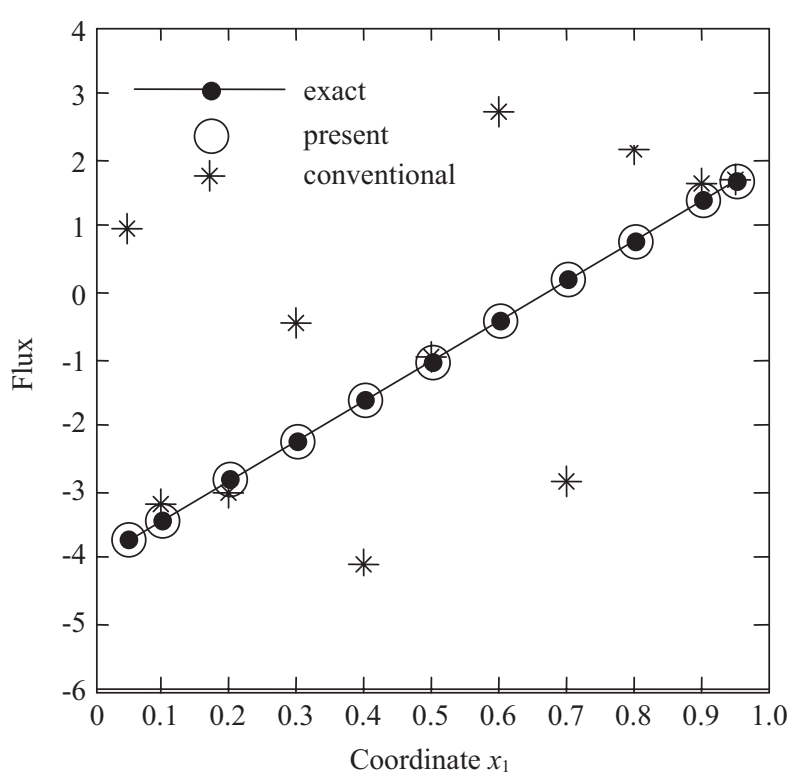

Fig. 5. $\partial u / \partial x_{1}$ at interior points on the line $x_{2}=5.0 \mathrm{E}-10$.

\section{CONCLUSION}

In this paper, a general algorithm in BEM for potential problem of thin bodies is presented. An equivalent non-singular BIEs and a general transformation have been presented to estimate the singular and nearly singular integrals which occur in the analysis of thin body problems. With the 


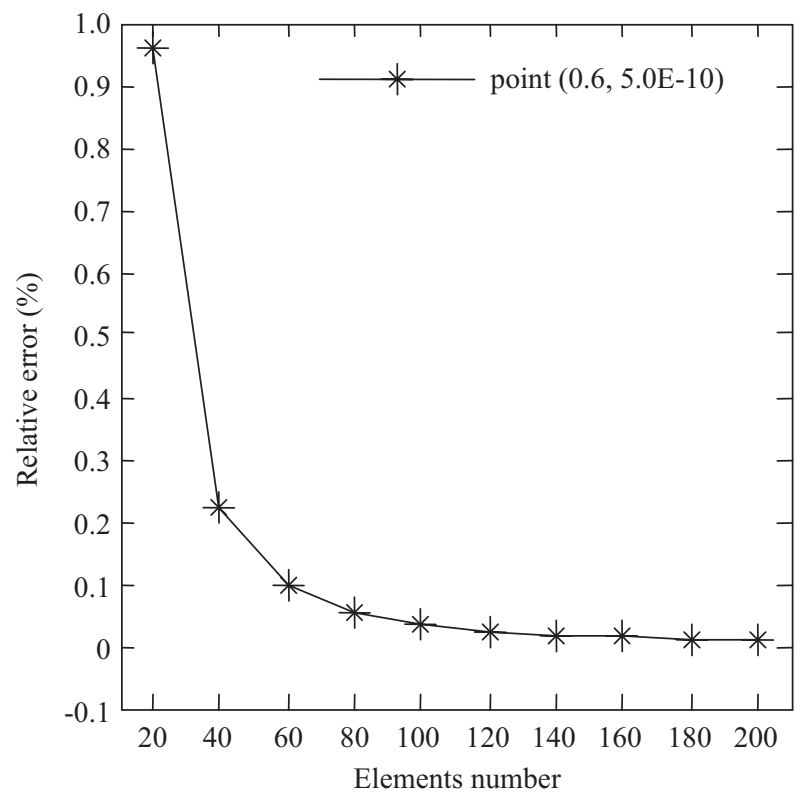

Fig. 6. Convergence curve of fluxes at points $(0.6,5.0 \mathrm{E}-10)$.

proposed method, the singularities of singular and nearly singular integrals are removed efficiently, and fairly high accuracy of numerical results is achieved. Numerical examples on heat conduction in thin domains with thickness-tolength ratios range from $1 \mathrm{E}-01$ to $1 \mathrm{E}-09$ are presented to test the proposed method, with which excellent results are obtained. The present method is also general and can be applied to other problems in BEM, which will be discussed later.

\section{ACKNOWLEDGMENTS}

The research is supported by the National Natural Science Foundation of China (10571110) and the Natural Science Foundation of Shandong Province of China (2003ZX12). The author wishes to express his gratitude with Professors JengTzong Chen and Chein-Shan Liu of Taiwan Ocean University for many valuable suggestions and directions.

\section{REFERENCES}

1. Brebbia, C. A., Tells, J. C. F., and Wrobel, L. C., Boundary Element Techniques, Springer-Verlag, Berlin, Germany (1984).

2. Chen, J. T., Chen, P. Y., and Chia, T. C., "Surface motion of multiple alluvial valleys for incident plane $\mathrm{SH}$-waves by using a semi-analytical approach," Soil Dynamics and Earthquake Engineering, Vol. 28, No. 3, pp. 58-72 (2008).

3. Chen, J. T. and Hong, H. K., "Review of dual boundary element methods with emphasis on hypersingular integrals and divergent series," Applied Mechanics Reviews, Vol. 52, No. 1, pp. 17-33 (1999).

4. Chen, J. T. and Shen, W. C., "Degenerate scale for multiply connected laplace problems," Mechanics Research Communications, Vol. 34, No. 1, pp.69-77 (2007).

5. Granados, J. J. and Gallego, G., "Regularization of nearly hypersingular integrals in the boundary element method," Engineering Analysis with Boundary Elements, Vol. 25, No. 3, pp. 165-184 (2001).
6. Hong, H. K. and Chen, J. T., "Derivations of integral equations of elasticity," Journal of Engineering Mechanics, ASCE, Vol. 114, No. 6, pp. 1028-1044 (1988).

7. Hsiao, S. S., Lin, M. C., and Hu, N. C., "Drbem analysis of combined wave refraction and diffraction in the oresence of current," Journal of Marine Science and Technology, Vol. 10, No. 1, pp. 54-60 (2002).

8. Huang, Q. and Cruse, T. A., "Some notes on singular integral techniques in boundary element analysis," International Journal for Numerical Methods in Engineering, Vol. 36, No. 15, pp. 2643-2659 (1993).

9. Jun, L., Beer, G., and Meek, J. L., "Efficient evaluation of integrals of order using gauss quadrature," Engineering Analysis, Vol. 2, No. 3, pp. 118-123 (1985).

10. Liu, C. S., "A modified collocation trefftz method for the Inverse cauchy problem of laplace equation," Engineering Analysis with Boundary Elements, Vol. 32, No. 9, pp. 778-785 (2006).

11. Liu, C. S., Chang, C. W., and Chiang, C. Y., "A regularized integral equation method for the inverse geometry heat conduction problem," International Journal of Heat and Mass Transfer, Vol. 51, No. 21, pp. 5380-5388 (2008).

12. Liu, Y. J., "Analysis of shell-like structures by the boundary element method based on 3-D elasticity: formulation and verification," International Journal for Numerical Methods in Engineering, Vol. 41, No. 3, pp. 541-558 (1998).

13. Liu, Y. J., "On the simple solution and non-singular nature of the BIE/ BEM-a review and some new results," Engineering Analysis with Boundary Elements, Vol. 24, No. 10, pp. $789-795$ (2000).

14. Lutz, E. L., "Exact gaussian quadrature methods for near-singular integrals in the boundary element method," Engineering Analysis with Boundary Elements, Vol. 9, No. 3, pp. 233-245 (1992).

15. Ma, H. and Kamiya, N., "Distance transformation for the numerical evaluation of near singular boundary integrals with various kernels in boundary element method," Engineering Analysis with Boundary Elements, Vol. 25, No. 4, pp. 329-339 (2002).

16. Mukerjee, S., Chati, M. K., and Shi, X. L., "Evaluation of nearly singular integrals in boundary element contour and node methods for threedimensional linear elasticity," International Journal of Solids and Structures, Vol. 37, No. 51, pp. 7633-7654 (2000).

17. Niu, Z. R., Wang, X. X., and Zhou, H. L., "A general algorithm for calculating the quantities at interior points close to the boundary by the BEM," (in Chinese), Chinese Journal of Theoretical and Applied Mechanics, Vol. 33, No. 2, pp. 275-283 (2001).

18. Sladek, V. and Sladek, J., Singular Integrals in Boundary Element Methods, Computational Mechanics Publications (1998).

19. Sladek, V., Sladek, J., and Tanaka, M., "Regularization of hypersingular and nearly singular integrals in the potential theory and elasticity," International Journal for Numerical Methods in Engineering, Vol. 36, No. 10, pp. 1609-1628 (1993).

20. Sladek, V., Sladek, J., and Tanaka, M., "Nonsingular BEM formulations for thin-walled structures and elastostatic crack problems," Acta Mechanica, Vol. 99, pp. 173-190 (1993).

21. Sun, H. C., Nonsingular Boundary Element Method, (in Chinese), Dalian University of Technology Press (1999).

22. Tanaka, M., Sladek, V., and Sladek, J., "Regularization techniques applied to BEM," Applied Mechanics Reviews, Vol. 47, No. 10, pp. 457-499 (1994).

23. Wang, W. H., Liou, J. H., Robert, S., and Ben, D., "Machine vibration induced underwater acoustic radiation," Journal of Marine Science and Technology, Vol. 8, No. 1, pp. 30-40 (2000).

24. Zhang, X. S. and Zhang, X. X., "Exact integrations of two-dimensional high-order discontinuous boundary element of elastostatics problems," Engineering Analysis with Boundary Elements, Vol. 28, No. 7, pp. 725732 (2004)

25. Zhang, Y. M. and Lv, H. X., "Novel regularized boundary integral equations for potential plane problems," (in Chinese), Applied Mathematic and Mechanics, Vol. 9, pp. 1017-1022 (2006).

26. Zhang, Y. M. and Sun, C. L., "A general algorithm for the numerical 
evaluation of nearly singular boundary integrals in the equivalent non-singular BIEs with indirect unknowns," Journal of the Chinese Institute of Engineers, Vol. 31, No. 3, pp. 437-447 (2008).

27. Zhang, Y. M. and Sun, H. C., "Theoretic analysis on virtual boundary element," (in Chinese), Chinese Journal of Computational Mechanics, Vol. 17, No. 1, pp. 56-62 (2000).

28. Zhang, Y. M. and Sun, H. C., "Analytical treatment of boundary integrals in direct boundary element analysis of plane potential elasticity problems," (in Chinese), Applied Mathematic and Mechanics, Vol. 6, pp.
664-673 (2001).

29. Zhou, H. L., Niu, Z. R., Cheng, C. Z., and Guan, Z. W., "Analytical integral algorithm in the BEM for orthotropic potential problems of thin body," Engineering Analysis with Boundary Elements, Vol. 31, pp. 739-748 (2007)

30. Zhou, H. L., Niu, Z. R., Cheng, C. Z., and Guan, Z. W., "Analytical integral algorithm applied to boundary layer effect and thin body effect in BEM for anisotropic potential problems," Computers and Structures, Vol. 86, pp. 1656-1671 (2008) 